\title{
Aspectos históricos da formação de professores de Matemática em São João del-Rei-MG ${ }^{1}$
}

\author{
Historical aspects of mathematics teachers' education in São João del Rei-MG \\ Paulo Henrique Apipe Avelar de Paiva ${ }^{2}$ \\ Maria Laura Magalhães Gomes ${ }^{3}$
}

\begin{abstract}
Resumo
Relatamos resultados de uma pesquisa sobre a formação de professores de Matemática no curso de Ciências da Fundação de Ensino Superior de São João del-Rei, no período 1987-2001. Estudamos, no âmbito desse curso, o momento da criação das habilitações em Física e Química e os benefícios trazidos por elas à formação matemática, focalizando ainda aspectos relativos aos corpos docente e discente. A investigação fez uso do aporte teórico-metodológico da História Oral e utilizou também documentação escrita. As análises mostram que as habilitações foram cruciais para uma mudança de patamar no curso de Ciências, antes considerado uma extensão do $2 .^{\circ}$ grau. No período abordado, o corpo discente se originava da própria região de São João del-Rei e a expansão do corpo docente trouxe força para uma instituição recém federalizada.
\end{abstract}

Palavras-chave: História da Educação Matemática; Formação de Professores; História Oral; São João del-Rei.

\begin{abstract}
We report results of a research on mathematics teachers' education in the course of Sciences offered by Fundação de Ensino Superior de São João del Rei, in the period 1987-2001. We studied the moment of the creation of special qualifications in Physics and Chemistry and the benefits brought by them to mathematics education. Moreover, we focus on aspects related to teachers and students. The research made use of theoretical and methodological contributions of oral history and also used written documentation. Our analysis shows that the qualifications were crucial for a step change in the course of Sciences, once considered a 2nd degree extension. In the period covered, most of the students came from the region of São João del Rei and the expansion of the faculty brought strength to a newly federalized institution.
\end{abstract}

Keywords: History of Mathematics Education; Teachers' Education; Oral History; São João del-Rei.

\section{Introdução}

O presente artigo resulta de uma investigação que visou analisar a formação de professores de Matemática na cidade de São João del-Rei, localizada na região central de Minas Gerais, durante o período compreendido entre 1987 e 2001. Mais especificamente, a

\footnotetext{
${ }^{1}$ Agência financiadora: Coordenação de Aperfeiçoamento de Pessoal de Nível Superior (CAPES)

${ }^{2}$ Mestre em Educação pela Universidade Federal de Minas Gerais (UFMG). Professor do Grupo Educacional Bom Jesus, em Curitiba-PR. País: Brasil. E-mail: apipep@ yahoo.com.

${ }^{3}$ Doutora em Educação pela Universidade Estadual de Campinas (UNICAMP). Professora do Departamento de Matemática e do Programa de Pós-Graduação em Educação da Universidade Federal de Minas Gerais (UFMG), em Belo Horizonte-MG. País: Brasil. E-mail: mlauramgomes@ gmail.com.
} 
pesquisa teve como objetivo reconstituir aspectos históricos da formação de professores de Matemática no curso de Ciências da Fundação de Ensino Superior de São João del-Rei (FUNREI) entre os anos 1987 e 2001. O período focalizado justifica-se por entendermos que o ano de 1987 marcou o início das atividades da Fundação e 2001 foi o ano imediatamente anterior ao da criação do curso de Licenciatura em Matemática e da instituição Universidade Federal de São João del-Rei (UFSJ). Portanto, tendo iniciado suas atividades em 2002, o curso de Matemática da UFSJ ainda não era o principal responsável pela formação de professores de Matemática no Campo das Vertentes ${ }^{4}$ no período por nós considerado.

Para tentar compreender como se deu a formação de professores de Matemática nessas condições, analisamos o momento de criação das habilitações em Física e em Química, bem como suas implicações para a formação matemática dos estudantes do curso de Ciências. Também nos debruçamos sobre os quadros docente e discente que compunham a FUNREI, buscando entender as contribuições dos professores para a instituição, particularmente para a Licenciatura em Ciências, e o perfil do alunado atendido.

Conhecer melhor a formação de professores de Matemática no curso de Ciências da FUNREI é fundamental para entender a formação desses profissionais no âmbito da cidade e, quiçá, da mesorregião e da microrregião em que fica São João del-Rei. Ao observarmos a localização da cidade, situada na microrregião homônima a ela, percebemos que esse centro urbano serviu e serve como polo ainda hoje, sendo, pois, referência importante para as localidades próximas em vários sentidos (educacional, comercial, hospitalar, dentre outros). Numa abrangência maior, há forte influência da educação sanjoanense também para a formação de novos docentes na mesorregião do Campo das Vertentes, uma vez que a cidade sempre dispôs de instituições formadoras de professores de várias áreas do Ensino Básico desde o início do século XX. Ademais, São João del-Rei, com sua história tricentenária, faz parte de uma região histórica bastante conhecida e privilegiada devido à corrida do ouro, principalmente no século XVIII, e também por ter sido berço da Inconfidência Mineira. Essas características nos fazem pressupor que a cidade teve, desde cedo, uma rotina movimentada.

Procuramos, então, compreender o percurso da formação de professores de Matemática na cidade, levando em conta aspectos acadêmicos, políticos e sociais da época focalizada. Para tal tarefa, utilizamo-nos de fontes escritas (de documentos, na concepção que Cellard (2010) lhes dá) e também de fontes orais, aproveitando que o período que propusemos estudar é recente e possibilitou o contato com pessoas que fizeram parte da rotina do curso de Ciências em algum momento. Trata-se de pessoas que participaram do processo de formação de professores de Matemática de nosso interesse. Levamos em consideração, em nosso trabalho, a grande potencialidade de suas narrativas. Nessa perspectiva, apoiamo-nos em Larrosa (2005), que alerta para a necessidade de quebrar o paradigma da experiência tomada como um conhecimento inferior, ou mesmo como um obstáculo para o verdadeiro conhecimento, e, em sentido oposto, dar legitimidade à

\footnotetext{
${ }^{4}$ Nome da mesorregião mineira à qual pertence a cidade de São João del-Rei.
} 
experiência, dar dignidade a ela. Em sintonia com essas ideias, utilizamo-nos da metodologia denominada História Oral, da qual falaremos brevemente a seguir.

\title{
Sobre História Oral, o caminho para as entrevistas e o uso de documentação escrita
}

\begin{abstract}
A necessidade da história oral se fundamenta no direito de participação social, e nesse sentido, está ligada ao direito de cidadania. Com uma vocação para tudo e para todos, a história oral respeita as diferenças e facilita a compreensão das identidades e dos processos de suas construções narrativas. Todos são personagens históricos, e o cotidiano e os grandes fatos ganham equiparação na medida em que se trançam para garantir a lógica da vida coletiva (Meihy, 2002, p. 20-21).
\end{abstract}

Ao optar pela História Oral, Janotti (2010) propõe que é necessário considerar, ao menos, três instâncias teórico-metodológicas que interagem e evidenciam a sua pertinência como metodologia: a instância dos depoentes, a do entrevistador e a do público. Entendemos que optar pela História Oral é considerar, no mínimo, essas três instâncias, e concordamos que há tensões constantes que circundam os testemunhos e são explicitadas em qualquer trabalho semelhante a este (Janotti, 2010). As tensões remetem aos depoimentos coletados, às informações neles contidas, à natureza dos depoimentos, ao discurso historiográfico a ser produzido e ao papel de cada parte. Cabe aos depoentes tecer considerações acerca do tema em questão, segundo suas próprias vivências, sua linguagem, tendo em vista finalidades ocultas ou não; o entrevistador vai em busca do testemunho e "domina técnicas e métodos, que precisam ser assegurados para a aceitação do público a que seu trabalho se destina" (Ibidem, p. 13).

Por meio da análise das narrativas dos depoentes que nos concederam entrevista, acreditamos que a História Oral nos proporcionou o acesso a testemunhos capazes de iluminar aspectos não evidenciados nos documentos escritos. Entretanto, "testemunhar não é apenas dizer o que viu ou ouviu, mas é também a construção de um discurso sobre o factual" (Janotti, 2010, p. 14). E quando a factualidade do indivíduo é a mesma compartilhada pelos grupos sociais aos quais ele pertence, o depoimento que outrora era exclusivamente dele (do indivíduo), ganha contornos sociais, ultrapassando o limite da individualidade (Halbwachs, 1990).

No entendimento de Garnica (2007), além de a História Oral ser um método de pesquisa qualitativo, a escolha dessa metodologia traz consigo algumas implicações importantes.

(...) optar pela História Oral, portanto, é optar por uma concepção de História e reconhecer os pressupostos que a tornaram possível. É inscrever-se num paradigma específico, é perceber suas limitações e suas vantagens e, a partir disso, (re)configurar os modos de agir de maneira a vencer as resistências e ampliar as vantagens. Portanto, não se trata simplesmente de optar pela coleta de depoimentos e, muito menos, de colocar como rivais a escrita e a oralidade. Trata-se de entender a História Oral na perspectiva de, face à impossibilidade de constituir "A" história, (re) construir algumas de suas várias versões, aos olhos dos atores sociais que vivenciaram certos 
DOI: http://dx.doi.org/10.20396/zet.v24i3.8648091

contextos e situações, considerando como elementos essenciais, nesse processo, as memórias desses atores - via de regra negligenciados -, sem desprestigiar, no entanto, os dados "oficiais", sem negar a importância de fontes primárias, de arquivos, de monumentos, dos tantos registros possíveis (Garnica, 2007, p.89).

Tentando reconstruir uma das várias versões da história da formação de professores de Matemática do curso de Ciências, realizamos entrevistas para colher testemunhos de oito professores e um aluno que fizeram parte do curso de Ciências da FUNREI em algum momento entre 1987 e 2001 . Sabemos que um grupo de professores atuou desde o período inicial e o professor Marco Túlio Raposo foi um deles. As indicações de alguns nomes por esse professor, caracterizando o processo que Garnica, Fernandes \& Silva (2011, p. 235) chamam de critério de rede, bem como os documentos escritos na época do curso de Ciências, foram primordiais para escolhermos nossos entrevistados. Além do professor Raposo, contamos com a colaboração dos professores Murilo Cruz Leal (in memoriam ${ }^{5}$ ), José Mauro da Silva Santos e Fernando Otávio Coelho, do Departamento de Ciências Naturais (DCNAT) da UFSJ. Professores que ainda hoje atuam no curso de Licenciatura Plena em Matemática, lotados no Departamento de Matemática e Estatística (DEMAT) e que, à época, eram professores do curso de Ciências, também se dispuseram a colaborar com a pesquisa tal é o caso dos professores Francinildo Nobre Ferreira, José do Carmo Toledo, Marco Antônio Claret de Castro e Romélia Mara Alves Souto. Tivemos também a participação de Aurélio José Pereira, um ex-aluno que concluiu a licenciatura curta em Ciências na FUNREI e, posteriormente, complementou seus estudos em Matemática.

Escolhemos essas pessoas para comporem nosso quadro de entrevistados utilizando os seguintes critérios: no caso dos professores de Matemática do curso de Ciências, pela sua constante atuação desde seu ingresso na FUNREI e pelo seu compromisso com a vertente do ensino na universidade; entre os professores de outras áreas, por terem ocupado cargos administrativos no curso e na universidade, de modo a ter a possibilidade de entender a estrutura da licenciatura em Ciências, bem como os propósitos a que se destinava um curso de formação de professores; no caso do ex-aluno, por ter complementado seus estudos para obter o grau de licenciado em Matemática e por ter escolhido a docência como profissão. Realizamos, com todos os nossos colaboradores, entrevistas semiestruturadas que, após a gravação, foram submetidas a um processo de transcrição e textualização ${ }^{6}$.

Às narrativas que obtivemos demos o mesmo tratamento que às fontes escritas ao tentar interpretá-las, compreendê-las e articulá-las para, assim, construir nossa história sobre a formação dos professores de Matemática da região escolhida. Baseando-nos em Gomes (2012), podemos afirmar que "nenhum tipo de documento retrata o que verdadeiramente se passou" (Gomes, 2012, p. 128, grifos no original) e, tampouco, os depoimentos orais são

\footnotetext{
${ }^{5}$ O professor Murilo Cruz Leal faleceu em janeiro de 2016, em São João del-Rei, poucos meses após concedernos a entrevista para a pesquisa.

${ }^{6}$ Grosso modo, nossas textualizações são versões editadas das entrevistas que coletamos, onde as marcas da oralidade foram suavizadas de modo a gerar um texto mais fluido.
} 
donos de tal veracidade sobre os fatos. Por isso, procuramos não valorar um tipo de fonte mais que outro.

As fontes escritas que utilizamos foram documentos da Divisão de Acompanhamento e Controle Acadêmico (DICON) da UFSJ; propostas pedagógicas e programas das disciplinas do curso de Ciências da FUNREI no período em foco; jornais e legislação educacional da época; documentos produzidos por professores e alunos dos cursos, tais como diários de classe, provas, notas de docentes e cadernos de antigos estudantes; acervos bibliográficos vinculados ao curso. Essa gama de fontes nos proporcionou um panorama do desenvolvimento do curso de Ciências ao longo de todo o período estudado.

"O documento permite acrescentar a dimensão do tempo à compreensão do social" (Cellard, 2010, p. 295) e o contato com a documentação constituída à época clareou também os limites temporais pelos quais deveríamos optar para que a investigação fosse viável, bem como iluminou caminhos que seria conveniente percorrer. Sabendo disso, consideramos, ao analisar os documentos escritos acima citados, além da dimensão temporal que eles nos fornecem, as condições de produção e a intencionalidade de cada um, de acordo com o que propõe Le Goff (1994).

Feitas essas considerações acerca do método adotado, para contextualizar nosso cenário de pesquisa, passamos a discorrer brevemente sobre a educação na cidade de São João del-Rei do final do século XIX até o surgimento da FUNREI e seu desdobramento em Universidade Federal de São João-del-Rei.

\section{A educação em terras sanjoanenses a partir do final do século $\mathrm{XX}$}

São João del-Rei era uma localidade privilegiada quando a questão era acolher instituições com a finalidade de formar os cidadãos locais por meio da educação. A Comarca do Rio das Mortes, segundo Brügger (2002) e Morais (2009), possuía, em meados do século XIX, cerca de 210.000 habitantes, e São João del-Rei, local de importância reconhecida, era responsável por parte significativa da educação da região. Gaio Sobrinho (2000) descreve com detalhes vinte escolas que funcionavam na cidade no século XIX. Uma localidade com essa quantidade de instituições de ensino, ainda no século XIX, quando contava com seus cerca de 16.000 habitantes $^{7}$, precisava começar a pensar na formação dos professores que atuavam na região.

Assim, já no início do século XX, vamos encontrar instituições instaladas na cidade que tinham, entre suas atividades, a preparação para o magistério. O mais antigo dos estabelecimentos de ensino em funcionamento, o Colégio Nossa Senhora das Dores (CNSD), foi inaugurado em 1898. Conforme atesta Arruda (2011), esse colégio, inicialmente, destinava-se à formação de mulheres e, inevitavelmente, tinha como uma das frentes de

\footnotetext{
${ }^{7}$ Graça Filho (2003) diz que a população da cidade diminuiu significativamente nessa época, em contraposição ao desenvolvimento e ao crescimento da econômico de São João. O autor atribui tal fato às novas demarcações territoriais que a região sofreu, que reduziram a dimensão territorial da cidade.
} 
trabalho a preparação de professoras para atuar no ensino conhecido à época como primário. Essa função perdurou até o período por nós considerado, mesmo tendo essa formação passado por mudanças ao longo dos anos.

Outro acontecimento importante a ser considerado é a criação e atuação da Faculdade Dom Bosco de Filosofia, Ciências e Letras (FDB) na cidade. Sua história remete à criação, em 1940, do Colégio São João, pelos padres salesianos. O colégio, inicialmente, abrigava seminaristas da congregação, funcionando sob a forma de internato durante seus trinta primeiros anos. Após esse período, passou a aceitar alunos que não fossem internos - alunos que não eram seminaristas, portanto. Depois de algum tempo, o internato foi extinto, tendo o externato funcionado até 1986, quando o colégio encerrou de vez suas atividades.

O Colégio São João, que mudou de endereço em 1943, incorporou à sua estrutura o Instituto Salesiano de Filosofia e Pedagogia (ISFP) em 25 de fevereiro de 1948. Depois de uma nova expansão do ISFP, em 1953 foi criada a FDB, com a finalidade inicial de formar profissionalmente os religiosos da congregação salesiana. Reconhecida por meio do Decreto n. 34.392 (1953), e inaugurada em 9 de março de 1954, dois anos depois do início de seus trabalhos a primeira instituição de ensino superior da cidade abriu-se também à educação externa, tendo, a partir daí, atendido a jovens da cidade e de suas cercanias (Gaio Sobrinho, 2000). Segundo Arruda

A possibilidade da formação ganharia reforço com a expansão do Instituto de Filosofia e Pedagogia, transformando-se em Faculdade Dom Bosco de Filosofia, Ciências e Letras em 09 de março de 1954. Sua finalidade, conforme estabelecido em regimento, foi habilitar professores para atuar nos colégios da região (Arruda, 2011, p. 35).

Ainda na época da FDB, mais precisamente em 1966, foi fundado o curso de Ciências, o qual concedia ao aluno que o concluía habilitação para, dentre outras atividades, lecionar Matemática (Licenciatura Curta) no segundo segmento do então ensino de $1 .^{\circ}$ grau. Segundo o professor Marco Túlio Raposo, em razão da indicação n. ${ }^{\circ} 46 / 74$ do Conselho Federal de Educação, cogitou-se criar habilitações plenas para os alunos formados em Ciências pela FDB, mediante uma complementação de seus estudos com uma carga de 1000 horas. Essa habilitação poderia ser, dentre outras, em Matemática. Assim, o curso de Ciências passaria a ser um ciclo básico, depois do qual o aluno poderia obter mais uma habilitação. Por razões de ordem administrativa, essa perspectiva - da criação da habilitação em Matemática não deu certo. Após essa tentativa frustrada de se criar um curso de Licenciatura Plena em Matemática, o curso de Ciências continuou, hegemonicamente na região, a formar professores de Matemática na licenciatura curta até o ano de 2003.

A FDB teve essa denominação até 1986, quando, por meio da Lei n. 7.555 (1986), juntamente com mais duas instituições, a saber, a Faculdade de Ciências Econômicas, Administrativas e Contábeis (FACEAC) e a Faculdade de Engenharia Industrial (FAEIN) ${ }^{8}$,

\footnotetext{
${ }^{8}$ A FACEAC data de 1972 e a FAEIN, de 1975. Ambas integravam a Fundação Municipal de São João del-Rei.
} 
foi estabelecida a Fundação de Ensino Superior de São João del-Rei (FUNREI). As três instituições, que passavam por dificuldades financeiras, se juntaram para formar uma só instituição, entregue à administração pública federal, e que passou a funcionar atendendo a uma gama maior de alunos. Os cursos das instituições anteriores foram mantidos e, apesar de a lei que a estabeleceu ser de 1986, a FUNREI teve sua data simbólica de criação instituída em 21 de abril de 1987. A partir da Lei n. 10.425 (2002), em 19 de abril de $2002^{9}$, a FUNREI foi nomeada Universidade Federal de São João del-Rei. Atualmente, o local que abrigou a FDB é o campus Dom Bosco da UFSJ.

Após o advento da UFSJ, o curso de Ciências foi perdendo força, ainda que tardiamente em comparação com outros cursos de Ciências que funcionavam na modalidade Licenciatura Curta ${ }^{10}$, ao mesmo tempo que a renovação advinda do surgimento da nova universidade contribuía para a criação do curso de Licenciatura em Matemática, ainda em 2002. Esse curso habilitava e continua habilitando seu concluinte a lecionar nas séries finais do Ensino Fundamental e no Ensino Médio. Antes disso, cabia ao graduado a complementação de sua formação, caso optasse pela docência no Ensino Médio.

Até onde pudemos investigar, a formação de professores especificamente de Matemática passou a se realizar de maneira mais sistemática em São João del-Rei a partir da criação do curso de Ciências, primeiramente aos cuidados da FDB e, posteriormente, sob a administração da FUNREI. Trazemos, a seguir, algumas considerações sobre a formação de professores de Matemática no curso de Ciências da FUNREI entre os anos de 1987 e 2001.

\section{Alguns aspectos da formação de professores de Matemática do curso de Ciências da FUNREI}

Após a criação da FUNREI, o curso continuou com o mesmo modo de funcionamento até 1991, no que tange à quantidade e à distribuição das disciplinas, bem como no que se refere à estrutura de operação. Ou seja, o aluno que ingressava estudava durante seis semestres e, ao final, obtinha seu grau acadêmico, estando apto a lecionar Ciências, Matemática e Desenho Geométrico da $5^{\mathrm{a}}$ à $8^{\mathrm{a}}$ série do $1 .^{\circ}$ grau $^{11}$. Segundo o professor Murilo $^{12}$, no início da FUNREI o curso de Ciências era um curso de estrutura simples, que estava levando para pessoas que não tinham uma boa formação de Ensino Médio, um ensino

\footnotetext{
${ }^{9}$ Informações disponíveis em: <http://www.ufsj.edu.br/dplag/historico.php>. Acesso em 05/10/2015.

${ }^{10}$ Estamos tomando por base os cursos de modalidade Licenciatura Curta da Universidade Federal de Mato Grosso do Sul (UFMS), descritos por Bittar \& Nogueira (2015), cujas atividades foram encerradas no início da década de 1980, e as discussões sobre as Licenciaturas Curtas no país, especialmente as encabeçadas pela SBPC em seu documento "Sugestões para a formação de professores da área científica para as escolas de $1 .^{\circ}$ e $2 .^{\circ}$ graus", de 1981, para crer que a Licenciatura Curta em Ciências da FUNREI encerrou suas atividades tardiamente.

${ }^{11}$ A docência no 2. ${ }^{\circ}$ Grau só era concedida em caráter precário, pelas antigas Delegacias de Ensino.

12 Destacamos com itálicos as falas dos entrevistados.
} 
melhor que o deles, mas, de algum modo, ainda ligado àquele, uma vez que algumas das (...) bibliografias eram livros de Ensino Médio. O professor Murilo, assim como os professores Toledo, José Mauro e Raposo, descreveram a bibliografia adotada no início do curso para as disciplinas das áreas de Ciências Naturais e Matemática. Apesar de não ser exclusivamente voltada a uma revisão dos conteúdos do $2 .^{\circ}$ grau, essa bibliografia tratava de temas afeitos à escolarização em nível secundário, de modo que conteúdos mais avançados de cada área não eram abordados ou não passavam de introduções aos assuntos.

Enquanto várias instituições públicas, como a UFMS (Bittar \& Nogueira, 2015), estavam discutindo o retorno aos cursos que formavam docentes para disciplinas específicas - muitos deles já tinham voltado ao modelo anterior de formação dos docentes da área das Ciências Naturais e da Matemática -, a FUNREI continuava a realizar a formação na Licenciatura Curta em Ciências em caráter terminal. Esse fato pode ser explicado pela trajetória da instituição, que, antes, como FDB, tinha uma vivência muito regionalizada, procurava atender aos interesses da sua localidade e não participava sistematicamente das discussões nacionais. Após a criação da FUNREI, houve maior contato com outras instituições superiores de ensino do país - seja por meio de acordos de cooperação, com docentes da FUNREI indo complementar a formação em programas de pós-graduação, seja por outros tipos de contato. Porém, uma instituição nova, que dava seus primeiros passos, tinha também outras urgências e precisava se estruturar para começar a pensar nessas questões.

Em meio às muitas mudanças que a FUNREI exigia, assim que ocorreu a federalização, professores mais próximos ao curso - os docentes lotados no Departamento de Ciências Naturais (DCNAT) - sentiram a necessidade de expandir seus horizontes de atuação e cogitaram a criação das habilitações específicas, que concederiam Licenciatura Plena a quem complementasse o curso de Ciências. Esses estudantes poderiam, a partir de então, atuar também no $2 .^{\circ}$ grau nas áreas específicas escolhidas. Ou seja, a autorização para lecionar no $2^{\circ}$ grau não teria mais caráter precário, atendendo às disposições da Resolução n. 30 (1974) do Conselho Federal de Educação. Assim, o curso de Ciências teria caráter terminal para quem fizesse tal opção e funcionaria como ciclo básico para as habilitações específicas, podendo ser complementado na própria instituição.

Contudo, propôs-se criar apenas habilitações em Física e em Química, não sendo contempladas as áreas de Biologia e Matemática. Isso, porque o professor Marco Túlio Raposo iniciou uma pesquisa em 1988, que foi finalizada em 1990 por outro professor, Gervásio Bassini Sobrinho, sobre as necessidades, quanto à formação de professores, do distrito geoeducacional 14 (DGE 14) - que engloba cidades mineiras desde Ouro Preto até o sul de Minas Gerais e essa pesquisa confirmou a urgência de formar professores de Física e Química para atuar no 2. ${ }^{\circ}$ grau.

Um dado que corrobora a conclusão da pesquisa dos professores e estende-a para o ano em que as habilitações começaram a funcionar pode ser encontrado no Censo Educacional de 1992 para o ensino superior. De acordo com esses dados, o DGE 14 abrigava 
seis cursos de Ciências e outros seis de Matemática; dois cursos de Física, dois de Química e dois de Biologia.

Os cursos de Matemática do DGE 14 tinham números muito parecidos com os dos cursos de Ciências. Apesar de não ser possível distinguir Licenciaturas de Bacharelados, o Censo Educacional mostra que a procura era grande pelos cursos de Matemática, e que a quantidade de formados em 1991 superava a quantidade de diplomados no curso de Ciências. Isso dá a entender que a área de Matemática se apresentava em uma realidade não tão difícil, em relação à falta de professores, se comparada à dos cursos de Biologia, Física e Química. Os cursos de Ciências Biológicas, apesar de serem apenas dois, número igual ao dos cursos de Física e Química, apresentavam uma grande procura, com 507 candidatos disputando as 75 vagas disponíveis no DGE 14 em 1992, o que dá um total de 6,76 candidatos/vaga. Em 1991, esses cursos diplomaram 33 alunos. A situação, de fato, era drástica para as áreas de Química e Física que, além de atrair menos candidatos para as mesmas 75 vagas disponibilizadas no DGE 14, formavam pouquíssimos estudantes. Em 1991, o curso de Química diplomou 11 alunos e o curso de Física formou somente 6 novos licenciados. O pequeno número de concluintes acarretava que profissionais formados em outros cursos assumissem a docência nas duas áreas mais carentes, sobretudo por falta de professores licenciados.

Dessa forma, a preocupação dos professores em proporcionar habilitação em Física e Química era totalmente pertinente e visava a contribuir para que a região suprisse a falta desses profissionais.

Após o levantamento de dados e toda a organização da extensa documentação recolhida, foi redigida, sob a coordenação do professor Gervásio Bassini Sobrinho, uma carta-consulta, na qual se propunha a criação das habilitações em Física e em Química no curso de Ciências, em 1990. Seis meses após sua submissão ao Ministério da Educação, obteve-se um parecer favorável. O vestibular de 1992 foi realizado já na perspectiva da existência da complementação do curso, e a partir de então o curso de Ciências começou a ganhar contornos diferentes daqueles do seu modelo inicial.

Na grade curricular dos estudantes que optavam pela complementação, o curso passou a ter quatro semestres a mais, o que aumentava sua duração para cinco anos. Os últimos semestres seriam destinados a estudos aprofundados em cada uma das duas novas habilitações. De um modo geral, não houve mudanças significativas no que diz respeito à organização, à estrutura curricular e à disposição das disciplinas do, a partir de então, ciclo básico do curso - Ciências, em relação ao modelo anterior. Como a primeira turma que já entraria com a possibilidade de complementar o curso com as habilitações ingressou em 1992, a partir de 1995 o curso passou a ter, em sua estrutura, os novos períodos - do sétimo ao décimo.

Talvez a maior das mudanças que a criação das habilitações tenha trazido esteja na forma como o curso passou a ser conduzido e visto. Antes e depois da criação das 
habilitações, o nome se manteve: Ciências. Contudo, a forma de encarar o curso mudou, e uma evidência disso está nas expressões usadas. Quando mencionamos o curso de Ciências, nossos entrevistados que dele participaram associam a expressão ao momento anterior à criação das habilitações. À medida que as novas habilitações eram consolidadas, as pessoas usavam os nomes delas para se referirem à Licenciatura em Ciências, mesmo em seu ciclo básico.

Anteriormente caracterizado como uma "extensão" do 2. grau, o curso passou, a partir do momento de criação das habilitações, a apresentar maior aprofundamento nas áreas de Ciências Naturais e Matemática, em consequência da demanda exigida pelas complementações. Novos textos passaram a fazer parte da rotina das disciplinas e impulsionaram o curso a um nível mais denso de discussão acadêmica. Até mesmo as disciplinas pedagógicas, que davam maior atenção a questões relativas à sala de aula, organização escolar, didática e temas afins à educação, sofreram alguma mudança ${ }^{13}$. Apesar de, aparentemente, essa não ser uma alteração tão ampla quanto a relatada para as disciplinas específicas de Física e Química, ao menos os estudantes passaram a contar com temas educacionais das áreas de Ensino de Física e Ensino de Química, cujo estudo era conduzido por professores das respectivas áreas. Tal é o caso dos professores Murilo Cruz Leal, Paulo César Santos Ventura e Silvania Sousa do Nascimento, pioneiros nessa área, no curso de Ciências.

Esse grupo de professores deu início, na FUNREI, a um movimento que procurava se debruçar sobre questões relativas ao ensino de áreas específicas, e que contribuiu diretamente para que a área de Educação Matemática passasse a ter presença na instituição. À época, os três docentes acima citados fundaram um centro intitulado Núcleo de Professores de Ciências e Matemática (NPC), cuja atuação envolvia propor atividades para professores do ensino básico, além de criar e manter um boletim mensal, no qual seus membros publicavam textos relacionados à Educação.

Ultrapassando a perspectiva de realização exclusiva de ações verticalizadas do ensino superior sobre o de $1 .^{\circ}$ e $2 .^{\circ}$ graus, o grupo contava, como membros, com alguns professores não universitários. Em outras palavras, o NPC não somente se encarregava de discutir e preparar materiais para contribuir com a educação hoje denominada básica, mas se articulava com os professores ao recebê-los como membros. Esse foi o caso da professora Romélia Mara Alves Souto, da área de Matemática, que, posteriormente, viria a se tornar professora da FUNREI e uma das primeiras docentes ligadas à Educação Matemática da instituição.

Mesmo não tendo tido acesso a qualquer trabalho ou boletim do NPC, sabemos por nossos depoentes, como o professor Murilo e a própria professora Romélia, que o grupo chamou a atenção para a necessidade da discussão de questões sobre a formação de professores nos cursos de licenciatura. Essa iniciativa foi responsável pela criação de

\footnotetext{
${ }^{13}$ Remetemos o leitor interessado em mais detalhes sobre esse assunto a Paiva (2016).
} 
DOI: http://dx.doi.org/10.20396/zet.v24i3.8648091

condições, sobretudo humanas, para que os futuros cursos de licenciatura específicos Biologia, Física, Matemática e Química - pudessem ser criados na UFSJ. Os excertos a seguir, extraídos do relato da professora Romélia, esclarecem a ação dos professores do NPC na formação de professores para essas áreas.

Esses professores foram pioneiros aqui na Universidade em tentar atualizar o currículo e a se preocupar com as questões pedagógicas nos cursos de formação de professores que, até então, eram conteudistas. (...) Eles eram interessados e já incentivavam a leitura e o estudo de artigos e de periódicos relacionados ao Ensino de Física que, naquela época, de todas as áreas que hoje existem - Educação em Química, Educação Matemática, Educação em Física, Educação em Biologia - era a mais forte (...) começaram a chamar as pessoas para a necessidade e importância da questão pedagógica nos cursos de formação de professores, muito negligenciada até então. (...)

Cada um de nós da área da Educação, que éramos muito poucos nos respectivos departamentos, nos unimos desde o início para desenvolver projetos juntos, para executar, dar cursos de capacitação para professores da rede pública. Então a gente fazia tantos projetos de extensão quanto era possível realizar.

A criação das habilitações em Física e em Química resultou também na chegada de vários professores para a FUNREI. Podemos dizer que a autorização para as habilitações começarem a funcionar e o momento de federalização de uma nova instituição acarretaram a autorização para a contratação de docentes não somente para o Departamento de Ciências Naturais, mas também para o Departamento de Matemática. Além de professores como Fernando Otávio Coelho, para o DCNAT, um exemplo de contratação para o DEMAT é o da professora Romélia Mara Alves Souto, que então passou a integrar o quadro de professores desse departamento.

Chegavam, também, professores experientes, que colaboraram para o desenvolvimento da instituição e, de modo particular, do curso de Ciências. Esse é o caso do professor José Luiz Aarestrup Alves. Aposentado no Departamento de Física da Universidade Federal de Minas Gerais (UFMG), o professor José Luiz já realizara o doutorado e era um professor e pesquisador experiente que contribuiu muito para que o curso de Ciências progredisse em sua estruturação e organização, assim como incentivou os colegas de departamento a procurarem se aperfeiçoar e a pesquisar. O professor José Luiz, nesse sentido, é apontado pelo professor Murilo como um personagem importante para a melhoria tanto do curso de Ciências quanto do DCNAT. Segundo o depoimento do professor Murilo, a chegada de outros professores, como o professor Aarestrup (...) trouxe uma contribuição legal. (...) o José Luiz marcou muito o DCNAT no sentido de encorajar: "Vamos ter um projeto de desenvolvimento, vamos fazer desse departamento um departamento forte, um departamento grande". Por isso ele foi muito importante.

Os professores contratados sem vínculo efetivo com a FUNREI eram poucos na época do curso de Ciências. Consequentemente, havia muito acúmulo de funções entre os que eram 
efetivos, na dinâmica de uma instituição que, embora nova, almejava crescimento rápido e preparava seus docentes para o desafio de promover o ensino, a extensão e também a pesquisa, de modo indissociável e o mais igualitário possível. Ao se referir à contratação de alguns professores substitutos para auxiliar nas atividades, o professor Raposo disse: na verdade, isso tem muito a ver com a situação que a gente vivia. É preciso lembrar que esse era o período do governo do professor Fernando Henrique Cardoso e que foi um momento de dificuldade de reposição de quadros, de muitos professores substitutos, e professores substitutos não assumiam encargos administrativos, só podiam dar aulas. Então não tinha escapatória, praticamente todo mundo do departamento - naquele instante éramos cerca de dezesseis, dezoito professores - todo mundo tinha algum encargo, além das aulas.

Esse processo durou praticamente todo o tempo em que a instituição permaneceu com o nome de FUNREI. No entanto, às vésperas de se tornar UFSJ, o corpo docente já se tornara mais qualificado. Em quase quinze anos (desde 1987), eram poucos os especialistas, menos ainda os apenas graduados e a grande maioria dos professores já eram mestres e doutores - os que não quiseram complementar a formação não o fizeram, geralmente, porque já estavam em fim de carreira, vislumbravam a aposentadoria e não viam a necessidade de se aperfeiçoar. A mudança ocorreu em um curto período e demandou um esforço grande dos docentes que permaneciam ativos e precisaram dar suporte para que outros pudessem ter a oportunidade de complementar sua formação. Nesse sentido, talvez um dos casos mais emblemáticos com os quais tivemos contato foi o do professor Marco Túlio Raposo que, após se afastar para o mestrado e concluir os estudos nesse nível da pós-graduação, sentia a necessidade de realizar também o doutorado. Como ele não poderia se afastar devido ao quadro pequeno de professores disponíveis naquela época, resolveu fazer o doutorado em Física na UFMG ao mesmo tempo que exercia suas atividades de professor na FUNREI e, já no fim do curso de doutorado, assumiu também o cargo de vice-diretor do Centro de Ensino. A excessiva carga de trabalho aqui exemplificada mostra algumas das dificuldades que os professores enfrentaram para conseguir se qualificar.

Se, por um lado, chegavam professores novos na instituição, vindos de vários lugares, por outro lado, os alunos do curso de Ciências da FUNREI apresentavam um perfil bastante regionalizado, do começo das atividades da nova Fundação de Ensino de São João del-Rei até meados da década de 1990. Eram alunos da cidade de São João del-Rei e do entorno, oriundos da própria microrregião. Essa foi uma característica não exclusiva do curso de Ciências, tendo estado presente em toda a FUNREI. Com o passar do tempo, a procura pelos cursos aumentou, junto com o status que a instituição passara a ter e, após 1994 os números eram bem distintos dos do começo - para a Licenciatura em Ciências não foi diferente. Todavia, o caráter regionalizado do alunado permanecia. Estudantes de lugares mais distantes vieram a frequentar os cursos quando da mudança de FUNREI para UFSJ, no momento em que a instituição passou a ter o status de universidade federal e, consequentemente, ganhou mais visibilidade.

Os dados da Comissão Permanente de Vestibular (COPEVE) da UFSJ mostram que, 
enquanto até 1990 o curso de Ciências não atraía mais de um candidato para cada vaga e apresentava demanda estável, a partir de 1991 o número de candidatos começou a aumentar. Com algumas variações, a demanda cresceu até o último vestibular realizado para o curso de Ciências, em 2001, atingindo o ápice no vestibular de 2000, com 6,72 candidatos/vaga, conforme mostra o gráfico abaixo.

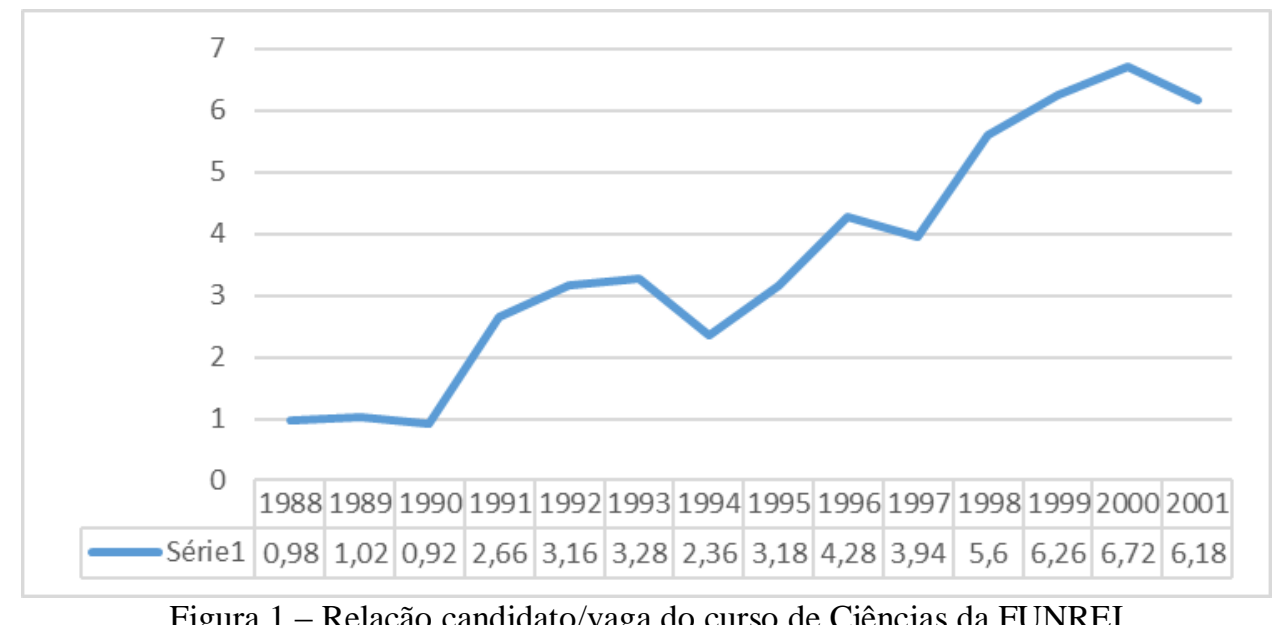

Figura 1 - Relação candidato/vaga do curso de Ciências da FUNREI

Fonte: Comissão Permanente de Vestibular da UFSJ.

Não é possível afirmar que a procura pela Licenciatura em Ciências tenha crescido quando foram criadas as habilitações em Física e em Química, pois em 1991 já se tinha verificado um aumento considerável na concorrência por uma vaga no curso: de 0,92 em 1990 para 2,66 no ano seguinte. O que podemos conjecturar é que vários alunos que exerciam a profissão docente anteriormente se matriculavam no curso para obter um diploma de nível superior, cumprindo um dos propósitos pelos quais o curso de Ciências foi criado - uma modalidade emergencial que levou formação superior, ainda que pouco aprofundada, a quem dela carecia. Esses professores-estudantes, cujo objetivo principal era o diploma, não conseguiam se envolver em outras atividades além das aulas. Em sua entrevista, o professor José Mauro declarou: (...) algo que sempre acontecia era vir aluno já trabalhando como docente e que estava precisando de diploma. Normalmente eram as pessoas mais maduras $e$ isso era um problema para o curso, porque eles queriam o diploma de qualquer jeito, estava fazendo falta para ele. Como o aluno já tinha um emprego e estava trabalhando, não estava muito preocupado com o curso. Ele estava preocupado em terminar e ter o diploma.

Entre os alunos do curso, os que não trabalhavam como professores geralmente exerciam atividades no comércio são-joanense e da região. Se, por um lado, o curso noturno dava a oportunidade para professores já em atuação se formarem, por outro lado, dificultava o êxito de outros projetos, pelo fato de os alunos do curso não terem condições de participar de atividades de pesquisa e extensão. A indisponibilidade dos alunos para tais atividades contribuiu para a relativa estagnação do panorama da pesquisa na FUNREI. Certamente havia estudantes que se dedicavam integralmente à formação em Ciências, porém eram poucos os alunos com esse perfil. Entre os que se enquadravam nessa categoria, havia os que se interessavam em participar de atividades além das aulas. Essa característica da licenciatura 
em Ciências trazia, como consequência, o fato de os alunos se formarem e, em sua maioria, começar - ou continuar - a lecionar Ciências e Matemática nas séries finais do $1 .^{\circ}$ grau ou Física ou Química no 2. ${ }^{\circ}$ grau, caso tivessem optado por algumas das habilitações. A pósgraduação, entre os discentes, não era muito difundida, sobretudo antes das habilitações, conforme o ex-aluno Aurélio relatou: saí e fui fazer a pós-graduação. Contudo, havia muito incentivo para se completar e pegar a Licenciatura Plena em Química ou Física. Agora, conversas a respeito de procurar fora outros estudos, eu (...) não me lembro. O professor Fernando disse que, após a criação das habilitações, perto dos últimos anos de existência do curso, a procura pela pós-graduação lato sensu e stricto sensu aumentou, com foco nas áreas de Física e Química. A área de Matemática se fazia presente apenas no ciclo básico do curso e, ao final dele, os estudantes que desejassem ministrar aulas de Matemática no $2{ }^{\circ}$ grau, ou mesmo continuar os estudos em nível de pós-graduação, precisavam procurar outras instituições, já que a FUNREI nunca ofereceu habilitação em Matemática.

\section{Considerações Finais}

O curso de Ciências da Fundação de Ensino Superior de São João del-Rei funcionou, durante os primeiros anos como instituição federalizada, com a mesma estrutura física e organizacional da qual usufruía anteriormente, à época da Faculdade Dom Bosco. Com organização simplificada e considerado uma extensão do $2 .^{\circ}$ grau, apesar do crescimento rápido da instituição, ainda se caracterizava pela regionalização durante o período de 1987 a 2001. As novas aspirações de uma instituição recém federalizada, unidas à referida vivência regionalizada, contribuíram para que o curso de Ciências se mantivesse como uma licenciatura que abrangia várias áreas, mesmo após esse tipo de curso ter sido extinto em muitas instituições brasileiras, dando lugar a cursos específicos para formar professores nas áreas de Física, Química, Biologia e Matemática.

As habilitações em Física e em Química surgiram de uma necessidade urgente da região em formar professores dessas áreas. As novas habilitações trouxeram consigo uma melhora consequente na formação dos estudantes, inclusive quanto ao conteúdo matemático. Além disso, foi nessa época que alguns professores começaram a se debruçar sobre as questões educacionais de modo mais sistemático. Entretanto, percebemos que o aprofundamento na formação matemática dos discentes se deu apenas como consequência das necessidades para a continuação do curso durante as habilitações. Isso dá a entender que a formação matemática era, de certa forma, secundarizada e realizada sob o signo da urgência, na mesma direção do que foi constatado em outros trabalhos como o de Cury (2011).

Notamos, pelos relatos de nossos entrevistados, o crescimento do quadro docente da instituição depois do momento em que ela foi entregue à administração pública federal. As novas contratações trouxeram professores em início de carreira, ao mesmo tempo que levaram a São João del-Rei professores experientes, dotados de vivência institucional em outros lugares e que encorajaram os que ali já estavam a complementar suas formações de forma a poder construir um projeto institucional forte, talvez sonhando com uma 
universidade, o que se concretizou posteriormente. Mesmo com o acúmulo de várias funções, os docentes da Fundação conduziram o curso de Ciências que, ao final de sua existência, foi responsável por formar grande parte dos professores que atuaram e atuam na região de São João del-Rei. Esses professores foram alguns dos principais atores sociais envolvidos na educação matemática escolar propiciada à população dessa região.

Embora o corpo docente tenha se expandido e, principalmente, se diversificado, o alunado recebido pela FUNREI e pela Licenciatura em Ciências continuou vindo da cidade e de sua região praticamente até o fechamento do curso, mesmo com o aumento da procura pelos cursos da instituição após 1994. Além disso, pudemos verificar que os alunos, via de regra, não se preocupavam em envolver-se em atividades para além das aulas. Esse fato contribuiu para que a pesquisa tivesse tido pouco progresso durante a existência da FUNREI.

A investigação que realizamos, baseada em documentos escritos e depoimentos orais, possibilitou vislumbrar novos horizontes de pesquisa a serem explorados futuramente. Alguns aspectos que podem ser pesquisados com mais profundidade são as várias habilitações do curso de Ciências, o currículo em geral e particularmente as disciplinas de formação pedagógica. Outro tema que se abre para a pesquisa a partir deste trabalho é o do desenvolvimento da primeira Licenciatura Plena em Matemática em São João del-Rei.

Acreditamos, portanto, que nosso trabalho representa uma contribuição para a compreensão da formação de professores de Matemática em São João del-Rei, ainda que esse tema indubitavelmente precise continuar a ser pesquisado.

\section{Referências}

Arruda, M. A. (2011). Formar almas, plasmar corações, dirigir vontades: o projeto educacional das Filhas da Caridade da Sociedade São Vicente de Paulo (1898-1905). Tese de Doutorado em Educação. Rio de Janeiro: Universidade do Estado do Rio de Janeiro.

Bittar, M. \& Nogueira, R. G. (2015). Um estudo da criação e desenvolvimento de Licenciaturas em Matemática na Universidade Federal de Mato Grosso do Sul. Bolema, 29 (51), 263-283.

Brügger, S. M. J. (2002). Minas Patriarcal: família e sociedade (São João del-Rei, séculos XVIII e XIX). Tese de Doutorado em História. Niterói: Universidade Federal Fluminense.

Cellard, A. (2010). A Análise Documental. In J. Poupart, J-P. Deslauriers, L. Groulx, A. Laperrière, R. Mayer \& A. Pires (org.). A Pesquisa Qualitativa: enfoques epistemológicos e metodológicos (pp. 295-316). Petrópolis: Vozes.

Cury, F. G. (2011). Uma história da formação de professores de Matemática e das instituições formadoras do estado do Tocantins. Tese de Doutorado em Educação Matemática. Rio Claro: Universidade Estadual Paulista Júlio de Mesquita Filho.

Decreto $n$. 34.392, de 27 de outubro de 1953. (1953). Concede autorização para funcionamento de cursos. Disponível em: 
DOI: http://dx.doi.org/10.20396/zet.v24i3.8648091

http://www2.camara.leg.br/legin/fed/decret/1950-1959/decreto-34392-27-outubro1953-326978-publicacaooriginal-1-pe.html.

Gaio Sobrinho, A. (2000). História da Educação em São João del-Rei. São João del-Rei: Setor de Gráfica da FUNREI.

Garnica, A. V. M. (2007). História Oral e Educação Matemática. In: M. C. Borba \& J. L. Araújo (org.). Pesquisa Qualitativa em Educação Matemática (pp. 77-98). Belo Horizonte: Autêntica.

Garnica, A. V. M., Fernandes, D. N. \& Silva, H. (2011). Entre a Amnésia e a Vontade de nada Esquecer: notas sobre regimes de historicidade e história oral. Bolema, 25(41), 213-250.

Gomes, M. L. M. (2012). Escrita Autobiográfica e História da Educação Matemática. Bolema, 26(42A), 105-137.

Graça Filho, A. A. (2003). Negociantes mineiros depois da travessia dos tempos coloniais. Teтpo, 8(15), 93-110.

Halbwachs, M. (1990). A Memória Coletiva. São Paulo: Edições Vértice.

Janotti, M. L. M. (2010). A incorporação do testemunho oral na escrita historiográfica: empecilhos e debates. História Oral, 13(1), 9-22.

Larrosa, J. (2005). Algunas notas sobre la experiencia y sus lenguajes. In: R. L. L. Barbosa. Trajetórias e perspectivas da formação de educadores (pp. 19-34). São Paulo: UNESP.

Le Goff, J. (1994). História e Memória. Campinas: Ed. Unicamp.

Lei n. 7.555, de 18 de dezembro de 1986. (1986). Autoriza o Poder Executivo a instituir a Fundação de Ensino Superior de São João Del Rei e dá outras providências. Disponível em: http://www.planalto.gov.br/ccivil_03/leis/L7555.htm.

Lei n. 10.425, de 19 de abril de 2002. (2002). Dispõe sobre a transformação da Fundação de Ensino Superior de São João del Rei em Fundação Universidade Federal de São João del Rei, e dá outras providências. Disponível em: http://www.planalto.gov.br/ccivil_03/leis/2002/L10425.htm.

Meihy, J. C. S. B. (2002). Manual de História Oral. São Paulo: Edições Loyola.

Morais, C. C. (2009). Posse e usos da cultura escrita e difusão da escola: de Portugal ao Ultramar, Vila e Termo de São João del-Rei, Minas Gerais (1750-1850). Tese de Doutorado em História. Belo Horizonte: Universidade Federal de Minas Gerais.

Paiva, P. H. A. A. de. (2016). Entre as memórias do Campo das Vertentes: uma história da formação de professores de Matemática da Fundação de Ensino Superior de São João del-Rei (FUNREI) no período de 1987 a 2001. Dissertação de Mestrado em Educação. Belo Horizonte: Universidade Federal de Minas Gerais. Acesso em 30 de novembro de 2016.2 Disponível em: http://www.bibliotecadigital.ufmg.br/dspace/bitstream/handle/1843/BUBDAA2NWR/disserta_o___paulo__ap_s_defesa.pdf?sequence $=1$ 
DOI: http://dx.doi.org/10.20396/zet.v24i3.8648091

Resolução n. 30, de 11 de julho de 1974. (1979). Fixa os mínimos de conteúdo e duração a observar na organização do curso de licenciatura em Ciências. In: G. V. F. AZEVEDO. Do ensino de $1^{o}$ grau: legislação e pareceres (pp. 489-492). Brasília: Ministério da Educação e Cultura. 